\title{
Cetacean surveys in the Southern Ocean using icebreaker-supported helicopters
}

\author{
Meike Scheidat • Ari Friedlaender • \\ Karl-Hermann Kock · Linn Lehnert • \\ Olaf Boebel $\cdot$ Jason Roberts $\cdot$ Rob Williams
}

Received: 4 August 2010 / Revised: 29 March 2011 / Accepted: 31 March 2011 / Published online: 17 April 2011

(C) The Author(s) 2011. This article is published with open access at Springerlink.com

\begin{abstract}
Cetaceans in the Southern Ocean are potentially impacted by anthropogenic activities, such as direct hunting or through indirect effects of a reduced sea ice due to climate change. Knowledge on the distribution of cetacean species in this area is important for conservation, but the remoteness of the study area and the presence of sea ice make it difficult to conduct shipboard surveys to obtain this information. In this study, aerial surveys were conducted from ship-based helicopters. In the 2006/07 (ANT XXIII/8) and 2008/09 (ANT XXV/2) polar summers, the icebreaker $\mathrm{RV}$ 'Polarstern' conducted research cruises in the Weddell Sea, which offered the opportunity to use the helicopters to
\end{abstract}

M. Scheidat $(\bowtie)$

Department of Ecosystems,

IMARES (Institute for Marine Resources and Ecosystem Studies), 1790 AB Den Burg, The Netherlands

e-mail: meike.scheidat@wur.nl

A. Friedlaender $\cdot$ J. Roberts

Duke University Marine Laboratory,

135 Pivers Island Road, Beaufort, NC, USA

K.-H. Kock

Institut für Seefischerei, Johann Heinrich von Thünen-Institut,

Palmaille 9, 22767 Hamburg, Germany

L. Lehnert

Forschungs- und Technologiezentrum Westküste,

Hafentörn 1, 25761 Büsum, Germany

O. Boebel

Alfred-Wegener-Institute for Polar and Marine Research,

Am Handelshafen 12, 27570 Bremerhaven, Germany

R. Williams

Marine Mammal Research Unit, University of British Columbia, Room 247, AERL, 2202 Main Mall, Vancouver,

BC V6T 1Z4, Canada conduct dedicated cetacean surveys. Combining the results from both cruises, over $26,000 \mathrm{~km}$ were covered on survey effort, 13 different cetacean species were identified, and a total of 221 cetacean sightings consisting of a total of 650 animals were made. Using digital photography, it was possible to identify four different beaked whale species and to conduct individual photo-identification of humpback and southern right whales. Helicopter surveys allow the collection of additional information on sightings, (e.g. group size, species), as well as the coverage of areas with high ice coverage. The flexibility and manoeuvrability of helicopters make them a powerful scientific tool to investigate cetaceans in the Southern Ocean, especially in combination with an icebreaker.

Keywords Cetacean - Distribution - Sea ice ·

Southern Ocean $\cdot$ Surveys $\cdot$ Whales

\section{Introduction}

The Southern Ocean provides critical habitat for a large number of whale populations, several of which have been previously reduced extensively in size during twentieth century whaling activities. Many of the cetaceans in the Southern Ocean still face anthropogenic impacts, such as direct hunting (Clapham et al. 2003) or through indirect effects of reduced sea ice due to climate change (Moore and Huntington 2008).

Knowledge on the distribution of cetacean species in this area is especially important for conservation, but survey conditions in the Southern Ocean are far from ideal. In addition to its remoteness, large areas are covered with sea ice that makes it logistically and economically challenging, or even impossible, to conduct large-scale shipboard surveys. 
This challenge has gained a greater sense of urgency in light of recent abundance estimates for Antarctic minke whales (Balaenoptera bonaerensis) (Branch and Butterworth 2001). There is some suggestion from the most recent set of circumpolar surveys conducted under the auspices of the International Whaling Commission (IWC) that this population has undergone a dramatic decline (Branch and Butterworth 2001), but there is considerable disagreement within the IWC's Scientific Committee whether the lower population size estimates are due to decreased abundance, changing survey methodology, or a shift in animal distribution due to changing sea ice conditions. Resolving this controversy, whilst of great importance for the IWC's management decisions, is challenging, because the ships used to conduct systematic surveys are unable to penetrate the sea ice. For many other cetacean species, it has been difficult to conduct comprehensive assessments due to lack of information on cetacean distribution both inside the marginal ice zone and north of $60^{\circ} \mathrm{S}$ (Branch and Butterworth 2001). Alternatively, aerial surveys using ship-based helicopters could allow information to be obtained on cetacean distribution relative to ice conditions that in turn could be used to estimate cetacean density across a range of habitats from open-water to ice-covered regions.

In the 2006/2007 and 2008/2009 polar summers, the icebreaker $R V$ Polarstern conducted two research cruises in the Weddell Sea. The ANT XXIII/8 cruise (26 November 2006-29 January 2007) and the ANT XXV/2 cruise (5 December 2008-5 January 2009) offered an opportunity to use the helicopters on board to conduct dedicated cetacean surveys, which were a secondary research objective to be met in combination with the surveys' obligation to resupply Neumayer station. The flights spanned open water, the marginal ice zone, as well as deep pack ice. Helicopter surveys have been used in Antarctic waters to survey pinnipeds in the fast ice and pack ice zones (Southwell 2005), but very few surveys have included cetaceans as target species (Plötz et al. 1991; van Franeker et al. 1997).

The goals of this paper are to: (1) introduce helicopter surveys as a viable means for conducting quantitative line-transect surveys of cetaceans in Antarctic waters; (2) illustrate the kind of data that can be obtained from such platforms; and (3) conduct a preliminary, exploratory analysis to identify factors that may influence distribution of different cetacean species with respect to sea ice. This latter analysis, whilst preliminary, is necessary to guide future data collection and analysis, particularly in the Weddell Sea where heavy ice conditions generally preclude vessels from being able to penetrate beyond the marginal ice edge zone. For this region, reliable information on how different cetacean species utilize this habitat is especially scarce.

\section{Methods}

Helicopter surveys and whale sightings

Surveys were conducted by means of a helicopter BO-105 from $R V$ Polarstern. The surveys could not follow a systematic sampling design (see below), but field protocols for recording effort and sightings data followed standard linetransect distance-sampling methods (Buckland et al. 2001). Flying time during each survey was generally around $2 \mathrm{~h}$, with a range from $20 \mathrm{~min}$ to $3.5 \mathrm{~h}$. Generally, surveys could not be designed in advance, because the ship's position and ice conditions were unavailable ahead of time, and because the cetacean surveys were not the main objective of the cruise. Therefore, track-lines were normally planned a few hours prior to departure to cover a rectangular shape (Figs. 1,2). The orientation and placement of these rectangles were arbitrary with respect to whale distribution (i.e. the ability to fly or not fly was a function of competing demands on the pilots' time, rather than being planned in response to seeing whales). Surveys were adapted in an ad hoc manner to changing weather and ice conditions and the course of $R V$ Polarstern through the ice. For safety reasons, these surveys usually employed a rectangular survey design that minimized the distance of the helicopter to the survey vessel at any given time. For the areas of Elephant Island and Larsen A and B ice shelves, surveys were conducted along pre-designed transects that involved equally spaced, parallel lines with a random start point, following specific depth gradients (Fig. 2).

Surveys were conducted at an approximate altitude of $183 \mathrm{~m}(600 \mathrm{ft})$ at a speed of $80 \mathrm{~km} / \mathrm{h}$. One observer was positioned in the back left seat of the helicopter and observed the area to that side of the helicopter. A second observer sat in the front left seat of the helicopter and observed the area ahead, focusing on the transect line. During the ANTXXV-2 survey, a third observer generally joined the team, sitting in the back seat on the right side. During the flights, the program VOR (designed by Lex Hiby and Phil Lovell and described in (Hammond et al. 1995) was used to enter all relevant survey data and to store the helicopter's GPS position every $4 \mathrm{~s}$.

Information on sea state (Beaufort Sea state scale), cloud cover (in octaves), glare (strength and area affected), ice coverage (in percent) and overall sighting conditions (good, moderate, poor) was recorded at the beginning of each survey and whenever conditions changed. Ice coverage was averaged for a search area $1 \mathrm{~km}$ in front of the helicopter, assessed by the front observer.

The following data was collected for each cetacean sighting: location, species, group size, group composition, behaviour, cue, swimming direction and reaction to the helicopter. Group composition described the presence of 


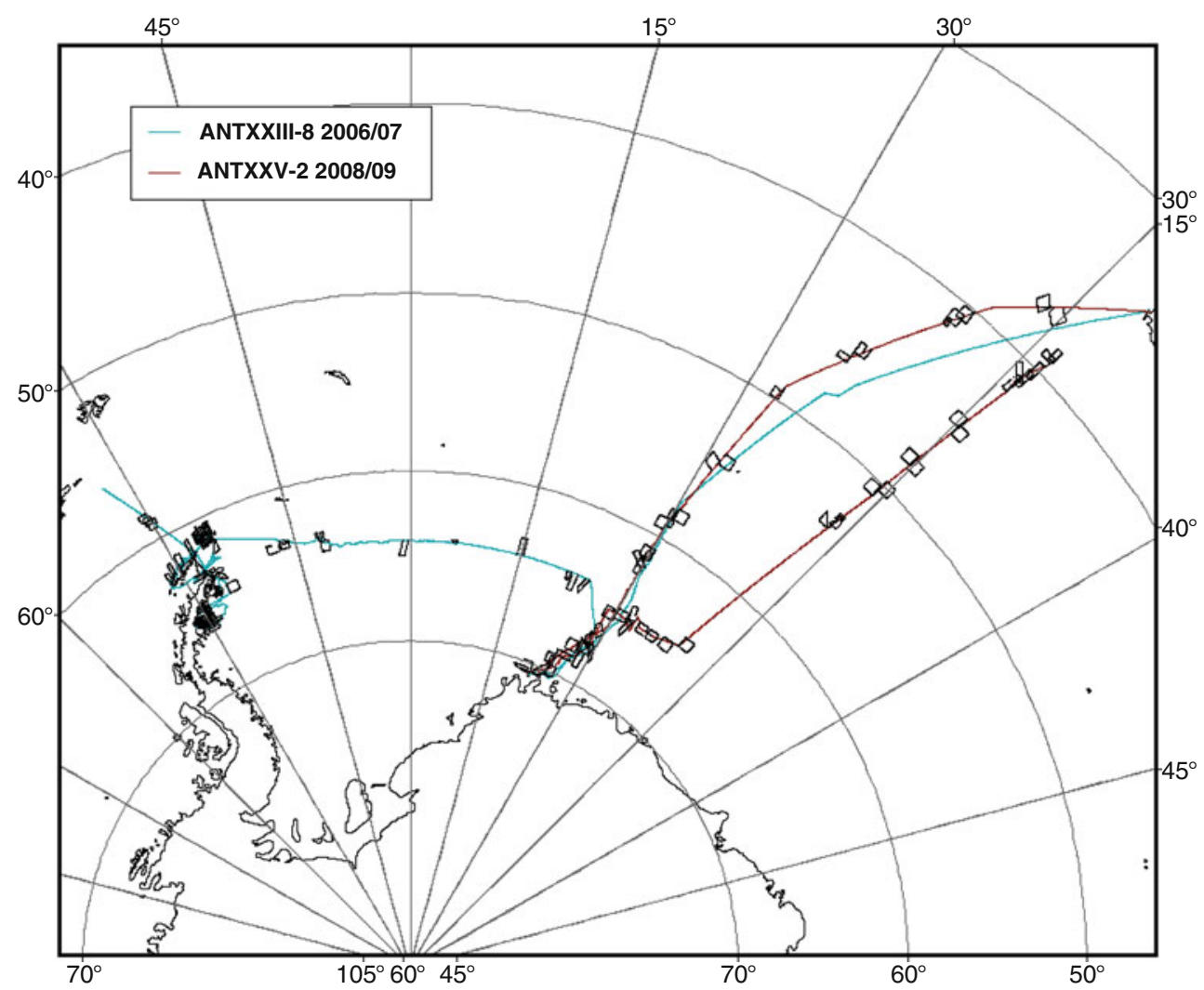

Fig. 1 Overview with vessel track and helicopter surveys for ANTXXIII/8 (2006/2007) and ANTXXV/2 (2008/2009)

calves or adults. Behaviour was categorised into directional swimming, non-directional swimming ("milling"), feeding and resting (including logging at the surface or slow swimming). The initial cue of a sighting included body under water, body at the surface, splash, footprint and blow. It was also noted if the helicopter was thought to cause a visible behavioural reaction in the animals. For the back observers, when a sighting was perpendicular to the trackline, the vertical angle in relation to the trackline was measured using an inclinometer. The front observer covered the area directly around the trackline (not visible to the back observers). The front observer would take the vertical angle to the sighting as well as the horizontal angle in relation to the trackline. All measurements were reported to the nearest degree. As the helicopter was at a consistent height, the measurements could be converted easily to perpendicular distances post-survey (Buckland et al. 2001). The survey was conducted entirely in 'closing mode', which means that if a sighting could not be identified to the species level at the first sighting, the helicopter left the trackline temporarily once the sighting was perpendicular to the trackline. The helicopter 'closed' on the sighting, approaching to identify species and group size. Photographs were taken to confirm species identity at a later time and the helicopter returned to the trackline to resume the survey. A digital tape recorder was used to provide an audio backup throughout each survey for later reference.

Ice covariate data and analysis methods

Two ice-related predictor variables were considered to explore the distribution and abundance of cetaceans with respect to sea ice conditions: ice concentration observed along the trackline by the helicopter ("ice_conc") and distance (in $\mathrm{m}$ ) to the marginal ice edge ("UBIceDist") observed by satellite remote sensing (defined by the smooth line inscribing the $15 \%$ ice concentration margin (Ainley et al. 2007)). We used observer-derived data for the ice concentration predictor, rather than remotely sensed data, because it is the operational measure: that is, the one that actually determines whether a ship could penetrate into the region, and thus conduct a full-scale visual survey for cetaceans.

To estimate the position of the marginal ice edge, we obtained daily, $6.25-\mathrm{km}$ resolution ice concentration images collected by the advanced microwave scanning radiometer for EOS (AMSR-E) satellite sensor from the University of Bremen (Spreen et al. 2008). We calculated the position of the ice edge for each daily satellite image with ArcGIS 9.3.1 Spatial Analyst functions (ESRI 2009) 
Fig. 2 Results of the combined helicopter surveys during the ANTXXIII/8 (2006/2007) and ANTXXV/2 (2008/2009) cruises: a Western Weddell Sea, b Eastern Weddell Sea and transit from South Africa


In order to explore the relationships between baleen by selecting the largest polygon of contiguous pixels having $\geq 15 \%$ ice concentration (i.e. the polygon encompassing the land-fast ice), extracting the outermost edge, and smoothing it using the Spatial Analyst "Boundary Clean" operator with the default parameters. We used the Marine Geospatial Ecology Tools software (Roberts et al. 2010) to match whale sightings to satellite images and calculate the distance to the closest ice edge for each sighting. whale presence and sea ice conditions, we ran a classification and regression tree (CART) analysis. This method has been used previously to not only determine the suitability of predictor variables for more rigorous multivariate analysis (e.g. Friedlaender et al. 2006) but also can be useful for determining thresholds for where the presence or absence of cetaceans occurs with respect to a continuous measure of 
a predictor variable (e.g. Hazen et al. 2009). Tree-based models use recursive partitioning methods to help resolve relationships of response variables to predictor variables by partitioning them into increasingly homogeneous subgroups (Breiman et al. 1984). CARTs are non-parametric in nature and therefore assume no a priori relationships between response and predictor variables, allowing for a variety of data to be used without requiring equal sample sizes amongst response variables (Guisan and Zimmermann 2000; Redfern et al. 2006).

For our CART, we chose to explore the relationships between baleen whale sightings with proximity to the marginal ice edge and the total concentration of sea ice where sightings were made. We also included a third predictor variable, proximity to shore ("UBLandDist"), defined as the distance (in $\mathrm{m}$ ) from the sighting to the closest land pixel in the AMSR-E ice concentration images. We chose to use individual sightings of each whale species as a binomial response variable. CARTs were run with optimal recursive partitioning and cross-validation methods similar (Hazen et al. 2009) to ensure that the most significant classifications were included in the final model. Likewise, receiver operator characteristic (ROC) curves were fitted to the sightings data, and the area under the curve (AUC) was calculated as a means to measure the likelihood of false positives in the CART (sensitivity versus specificity). In this measure, an AUC value of 1.0 would indicate no chance of false positives, whilst a 0 value would represent only false positives.

\section{Results}

During cruise ANT XXIII/8, 'Polarstern' entered the pack ice at $58^{\circ} \mathrm{S}$ and passed through approximately $2,200 \mathrm{~km}$ of ice in the eastern Weddell Sea to reach Neumayer Station $\left(70^{\circ} 39^{\prime} \mathrm{S}, 08^{\circ} 15^{\prime} \mathrm{W}\right)$ on the Antarctic shelf ice. From Neumayer Station, the vessel continued in a north-westerly direction until the vessel left the pack ice southwest of Elephant Island (see Fig. 1). From 1 December 2006 to 26 January 2007, a total of 58 aerial survey flights covering 13,057 km were conducted (Fig. 1).

During cruise ANT XXV/2, the helicopter survey started on 6 December 2008 and ended on 3 January 2009. The cruise track of the outward voyage followed an almost straight line from $57^{\circ} \mathrm{S}$ to Neumayer Station (see Fig. 2). The return voyage took place further to the East returning to Cape Town again in the morning of 5 January 2009. Surveys were slightly longer during this cruise covering $13,359 \mathrm{~km}$ in a total of 47 flights (Fig. 1).

During both surveys combined, a total of 221 cetacean sightings consisting of a total of 650 animals were made. In total, 13 different cetacean species were identified in both
Table 1 Overview of cetacean sightings and number of animals as recorded during two helicopter surveys conducted during ANTXXIII/8 (2006/2007) and ANTXXV/2 (2008/2009)

\begin{tabular}{|c|c|c|c|}
\hline Species (scientific name) & \# Sighting & \# Animals & Calves \\
\hline $\begin{array}{l}\text { Fin whale } \\
\quad \text { (Balaenoptera physalus) }\end{array}$ & 26 & 75 & 6 \\
\hline $\begin{array}{l}\text { Sei whale } \\
\quad \text { (Balaenoptera borealis) }\end{array}$ & 2 & 5 & 2 \\
\hline $\begin{array}{l}\text { Antarctic minke whale } \\
\quad \text { (Balaenoptera bonaerensis) }\end{array}$ & 94 & 183 & 0 \\
\hline $\begin{array}{l}\text { Humpback whale } \\
\quad \text { (Megaptera novaeangliae) }\end{array}$ & 53 & 134 & 2 \\
\hline $\begin{array}{l}\text { Southern right whale } \\
\text { (Eubalaena australis) }\end{array}$ & 1 & 2 & 1 \\
\hline $\begin{array}{l}\text { Sperm whale } \\
\quad \text { (Physeter macrocephalus) }\end{array}$ & 6 & 15 & 0 \\
\hline Unidentified large whale & 20 & 30 & 0 \\
\hline $\begin{array}{l}\text { Southern bottlenose whale } \\
\text { (Hyperoodon planifrons) }\end{array}$ & 5 & 10 & 0 \\
\hline $\begin{array}{l}\text { Gray's beaked whale } \\
\text { (Mesoplodon grayi) }\end{array}$ & 1 & 5 & 0 \\
\hline $\begin{array}{l}\text { Strap-toothed whale } \\
\quad \text { (Mesoplodon layardii) }\end{array}$ & 2 & 6 & 0 \\
\hline $\begin{array}{l}\text { Arnoux's beaked whale } \\
\text { (Berardius arnuxii) }\end{array}$ & 1 & 4 & 0 \\
\hline Killer whale (Orcinus orca) & 6 & 37 & 0 \\
\hline $\begin{array}{l}\text { Rough-toothed dolphin } \\
\text { (Steno bredanensis) \& } \\
\text { common dolphin (Delphinus sp.) }\end{array}$ & 3 & 143 & $>1$ \\
\hline Unidentified small cetacean & 1 & 1 & 0 \\
\hline Total & 221 & 650 & 12 \\
\hline
\end{tabular}

surveys combined. An overview of all sightings is given in Table 1.

Whale sightings in relation to ice conditions

The CART was used to relate the number of sightings of the three most commonly observed baleen whale species (minke, humpback and fin) to two ice-related, environmental response variables, ice concentration and distance to the ice edge, and to one other variable, distance to shore (Fig. 2). The other baleen whale species that were not included were observed fewer than 3 times (i.e. not frequently enough to include in a statistical model). We included 171 cetacean sightings, and the best-fit model determined by optimal recursive partitioning had an $R$-squared $=0.681$ with 5 splits. The first fundamental split in the tree occurred at a distance of $\sim 143 \mathrm{~km}$ from the ice edge (Fig. 3). The majority of cetaceans ( 75 of 76) found farther than this threshold distance were humpback and fin whales. Of the remaining 95 sightings made within this distance to the ice edge, 92 were minke whales. Of these 95 sightings, 84 were made in ice cover $>5 \%$, all of which were minke whales. In the ROC analysis 


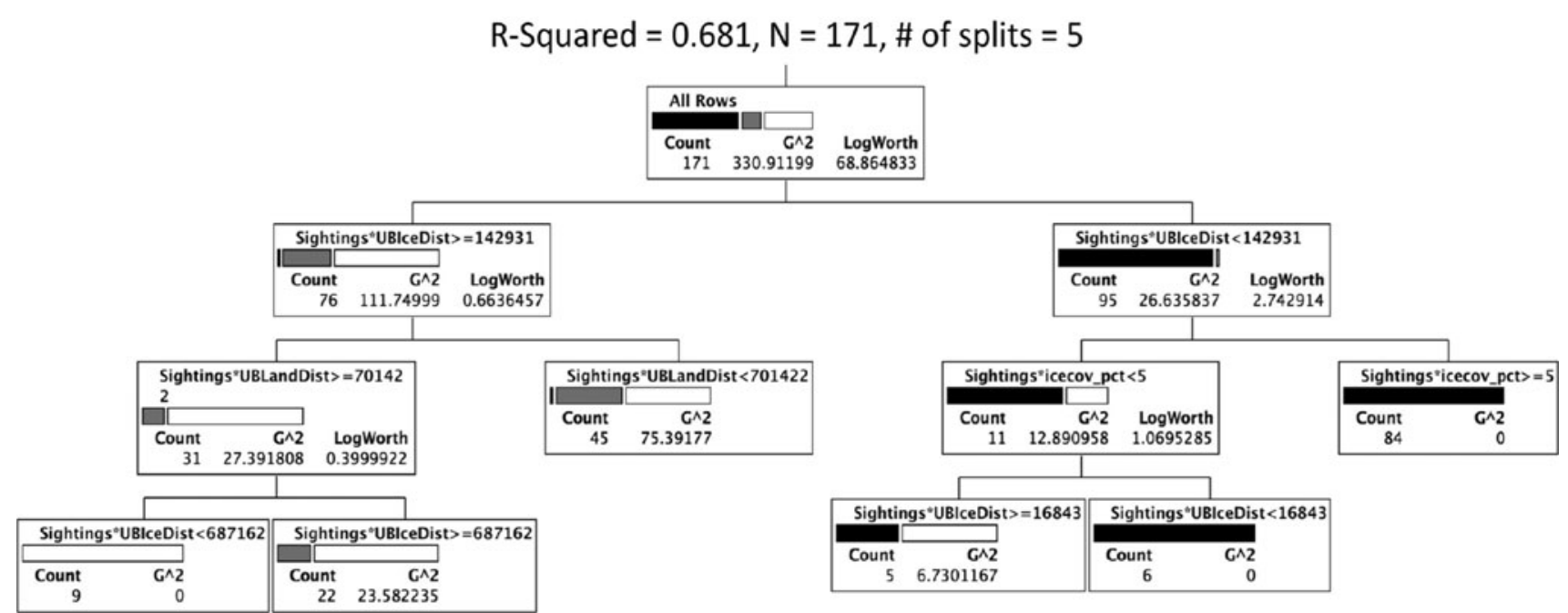

Fig. 3 CART diagram showing the relationships between three cetacean species and sea ice. Black bars represent Antarctic minke whales, grey bars represent fin whales and white bars represent humpback whales. The $R$-squared value and number of splits are generated from the optimal recursive partitioning function to generate the best-fit mod-

for minke whales, the CART yielded an AUC of 0.96, indicating that the CART performed very well at classifying whether a sighting was a minke or another species, given the input predictor variables.

The spatial distribution of the various cetacean species was distinct. Minke whales were encountered only in waters south of $57^{\circ} \mathrm{S}$, and most sightings were made in or close to sea ice (Fig. 4). Beaked whale sightings ranged from $50^{\circ} \mathrm{S}$ to $61^{\circ} \mathrm{S}$, with most sightings in a small area north of the South Shetland Islands. The large baleen whales were found in open water throughout the study area, but were not sighted further south than $63^{\circ}$. For humpback and fin whales, two areas of high density were found: one around the South Shetland Islands (Fig. 2) and the other on the most eastern part of the survey, at latitude of about $53^{\circ} \mathrm{S}$ (Fig. 2 continued). Killer whales were observed at both higher and lower latitudes.

Only four species were observed in ice-covered waters, mainly in the Weddell Sea and near the edge of the Larsen A and B ice shelves: Antarctic minke whale, Arnoux's beaked whale (Berardius arnuxii), Southern bottlenose whale (Hyperoodon planifrons) and killer whale (Orcinus orca) (Fig. 2).

The initial sighting cue of most of the identified sightings was the body at the surface of the water. This was followed by blows for large whales, footprints for the Antarctic minke and body under the surface for small and beaked whales (Table 2). Behaviour varied between species as well. Most animals were swimming directionally and a large proportion was logging at the surface or resting or swimming slowly (Table 2). When the helicopter passed animals in survey mode, in three cases, a visible reaction $\mathrm{el}$ of the data. Counts indicate the total number of sightings that were used for each split, and the proportion of each species is shown in each box e.g. for sightings $<142,931 \mathrm{~m}$ from the ice edge and ice cover $>5 \%, 84$ sightings were made and all were minke whales (black bar)

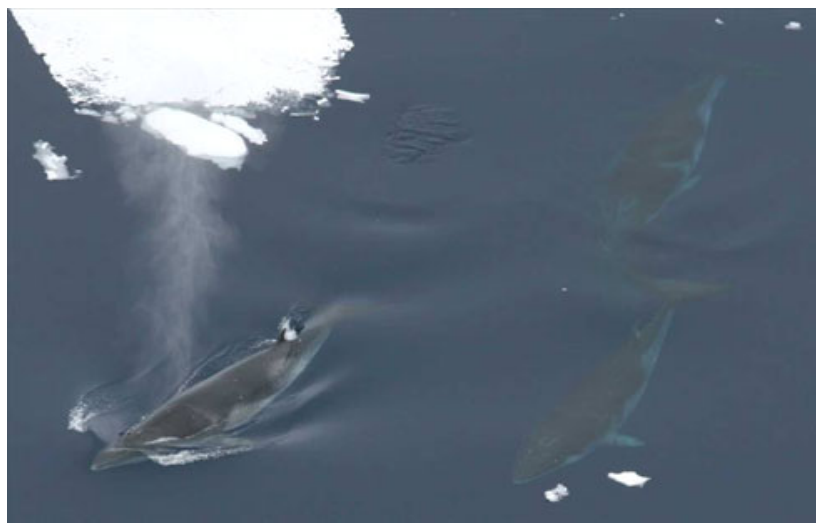

Fig. 4 Photograph of a group of Antarctic minke whales taken from the helicopter in the sea ice of the Weddell Sea

(fluke up, increase in swimming speed, change in swimming direction) to the helicopter was recorded. For all these sightings, the distance to the helicopter was less than $500 \mathrm{~m}$. When positioning the helicopter to take photographs, reactions were observed for two beaked whale groups. Whilst lying horizontally just at the water surface, animals synchronously changed their orientation in the water towards the helicopter and dove after a few minutes.

Digital photography from the helicopter offered ability to confirm visual estimates of group size. Mean group sizes varied between the different species (Table 2). Humpback whales had a maximum group size of 11 ; fin whales and Antarctic minke whales, 7 animals; sperm whales, 6 animals; and sei whales, 3 animals. Killer whale group sizes ranged from 1 animal (an adult male) to 18 (Table 2). 
Table 2 Overview of distribution of cues, behaviour and group sizes of large whales (fin whale, sei whale, humpback whale, southern right whale, sperm whale); Antarctic minke whale; small whales (killer whales, dolphins) and beaked whales as observed during the ANTXXIII/8 (2006/2007) and ANTXXV/2 (2008/2009) helicopter based surveys

\begin{tabular}{|c|c|c|c|c|}
\hline & Large whales & $\begin{array}{l}\text { Antarctic } \\
\text { minke whale }\end{array}$ & Small whales & Beaked whales \\
\hline & \multicolumn{4}{|l|}{ Cue } \\
\hline & $N=94$ & $N=77$ & $N=9$ & $N=8$ \\
\hline Body at surface $(\%)$ & 48 & 71 & 78 & 62 \\
\hline Body under surface $(\%)$ & 2 & 9 & 22 & 38 \\
\hline Blow $(\%)$ & 45 & 0 & 0 & 0 \\
\hline Footprint (\%) & 0 & 20 & 0 & 0 \\
\hline \multirow[t]{3}{*}{ Splash (\%) } & 5 & 0 & 0 & 0 \\
\hline & \multicolumn{4}{|l|}{ Behaviour } \\
\hline & $N=86$ & $N=79$ & $N=9$ & $N=9$ \\
\hline Directional swimming (\%) & 57 & 44 & 89 & 22 \\
\hline Un-directional swimming (\%) & 2 & 16 & 0 & 33 \\
\hline Resting (\%) & 28 & 35 & 11 & 44 \\
\hline Feeding $(\%)$ & 6 & 4 & 0 & 0 \\
\hline \multirow[t]{3}{*}{ Other (breaching) (\%) } & 7 & 0 & 0 & 0 \\
\hline & \multicolumn{4}{|c|}{ Group size and composition } \\
\hline & $N=107$ & $N=94$ & $N=10$ & $N=9$ \\
\hline Average group size & 2.46 & 1.95 & 18.10 & 2.78 \\
\hline Range of group size & $1-11$ & $1-7$ & $1-110$ & $1-5$ \\
\hline
\end{tabular}

Using digital photography from the helicopter, it was possible to later confirm species (Fig. 4). This was especially useful for the identification of four beaked whale species seen during the survey. Digital photography was also used for individual photo-identification of three humpback whales and one southern right whale mother-calf pair. Photographs were then compared with existing photo-identification catalogues in South America and South Africa. One humpback whale identified close to the South Shetland Islands was matched with an individual identified off the coast of Ecuador (pers. comm. Fernando Felix). One southern right whale female was matched with an individual recorded in South African waters in 1981 and 1996 (pers. comm. Peter Best).

\section{Discussion}

Helicopter surveys conducted from the $R V$ Polarstern proved valuable in several respects. The helicopter allowed the coverage of a broad study area in the comparatively short period of a few hours, as opposed to ship-borne surveys, which would take several days to cover the same area. Also, the helicopter survey effort was independent of the coverage of sea ice. Whilst a vessel would have to adapt survey speed and course, the helicopter can stay at a standard protocol even when crossing high sea ice coverage.
Thus, our surveys spanned completely open waters as well as those completely covered by ice and were not restricted to open-water habitats more easily accessed by the ship. Generally speaking, the areas surveyed in this study could not have been surveyed by conventional sighting ships as used in IWC surveys (Branch and Butterworth 2001). Whilst ship-based observations would be possible under similar sea ice conditions, ice-breaking operations generate substantial noise that has been shown to alter distribution of some whales (e.g. studies of ice-breakers and bowhead whales (Richardson et al. 1995)), which would compromise one of the major objectives of our study.

To conduct a successful survey, it is essential to use a good survey design that can be challenging in complex habitats (Thomas et al. 2007). The design we developed can be adapted shortly before (and even during) each survey flight, for example, to account for varying and complex sea ice conditions or in order to avoid poor local weather conditions. The resulting coverage results in data spanning a wide range of ice conditions, but is nevertheless spatially biased. There are spatial modelling methods that can use ice data together with the distance-sampling data to model habitat use of Antarctic cetaceans, in particular the Antarctic minke whale (Hedley et al. 1999; Williams et al. 2006). But methods to generate robust estimates of absolute abundance from such spatially biased data are still in development (Bravington and Hedley 2009). We have initiated 
collaborations that will take advantage of these complex statistical models to better understand the distribution and abundance of cetaceans in the Weddell Sea after accounting for unequal coverage probability and rapidly changing ice conditions (Bravington and Hedley 2009). In the meantime, our exploratory analyses using CARTs reveal distribution patterns that can allow us to generate specific hypotheses regarding how different cetacean species use and are affected by changing ice conditions in the Weddell Sea. Furthermore, we can now develop an analytical framework to compare the ecological interactions between cetaceans and their environment across very different Antarctic regions. The strong physical differences between regions such at the Weddell Sea, Western Antarctic Peninsula, and Ross Sea, for example, will have profound effects on the community structure, distribution and abundance of cetaceans (and other krill predators). Understanding regional differences can allow for predictive models and hypotheses to be tested regarding how different systems will respond to changes in environmental conditions.

Recent studies have shown that the distribution of baleen whales around the Antarctic Peninsula are related to physical features as well as prey availability (Thiele et al. 2004; Friedlaender et al. 2006) and that strong three-dimensional differences in these associations are found between humpback and minke whales in coastal waters (Friedlaender et al. 2009). The sea ice conditions between the Weddell Sea and the Western Antarctic Peninsula are dramatically different. Likewise, the oceanographic processes governing the circulation patterns and productivity of each region are very different, and thus we expect differences in the communities of top predators (including cetaceans) in each region. Whilst the distribution of prey is known to have the greatest influence on the distribution of cetaceans on the Western side of the Antarctic Peninsula, the heavy and multi-year ice conditions found in the Weddell Sea will likely shape a very different cetacean community and affect the distribution and abundance of the species present. Whereas humpback whales are the most common cetacean species in the waters around the Western Antarctic Peninsula in summer (Friedlaender et al. 2009) and fall (e.g. Thiele et al. 2004; Friedlaender et al. 2006), we find minke whales to be the most commonly seen cetacean in the Weddell Sea. Similar to Friedlaender et al. (2010) from the western side of the Antarctic Peninsula, we find that minke whale distribution is most influenced by proximity to sea ice cover in the Weddell Sea.

In our current study, we demonstrate a horizontal separation of minke from other baleen whales with respect to proximity to sea ice. This is in contrast to previous work around the Antarctic Peninsula that specifically looked at areas where minke and humpback whales were sympatric (e.g. Friedlaender et al. 2006, 2009). The differences in whale community structure in the current paper are likely the result of both seasonal and spatial differences in when and where the studies were conducted. The current study took place during the middle of summer when the marginal ice edge is retreating, and pack ice from the previous year has completely consolidated. Friedlaender et al. (2006, 2009) drew conclusions from data collected in the late autumn when ice was beginning to form for the upcoming winter. Likewise, our data were collected in the Weddell Sea, as opposed to the Western side of the Antarctic Peninsula, and the dramatic oceanographic differences in these regions likely contributes to both differences in the physical structure of sea ice and the distribution of cetaceans in the regions. Thus, the differences presented here in the distribution of different cetacean species that rely heavily on a common resource (Antarctic krill) are new and insightful. A more comprehensive analysis including measurements of prey would offer further information regarding the regional differences in cetacean distribution across the Antarctic.

As a survey platform, helicopters offer a unique and effective means of covering large areas in a short period of time. Being based on oceanographic research vessels allows helicopters to cover far-reaching areas not accessible from land-based stations. Likewise, helicopter surveys can be paired with oceanographic and environmental sampling strategies that can only be accomplished by dedicated time on research vessels. If the research vessel stays in the same area for an extended period of time, for example during dedicated research programs, study areas can also be covered using a predetermined survey design and quantitative analyses can be conducted to better understand the distribution and abundance patterns of cetaceans in relation to their environment. During the ANT XXIII/8 cruise two such research programs were conducted, one around Elephant Island investigating fish fauna, and one in the Larsen $\mathrm{A}$ and $\mathrm{B}$ area investigating the effects of the collapse of the Larsen ice shelves (Gutt 2008; Gutt et al. 2011). As the vessel spent several weeks in each of the areas, we changed our ad hoc survey design to parallel tracklines in a way to ensure representative coverage. In the future, this will allow local whale abundance to be estimated using relatively simple, conventional distance-sampling analyses.

The helicopter platform allowed good observations of cetaceans above water and underneath (see Fig. 4, Antarctic minke whales surfacing and under water). For a considerable proportion of sightings of small cetaceans and beaked whales, the main cue was the body under water, indicating that helicopter surveys are able to detect cetaceans just under the water surface when they would not be visible from an observer on a vessel. This is particularly important for species that either do not show easily recognisable surface cues (e.g. blows of large baleen whales) or that spend only little time at the surface (e.g. beaked whales). This is 
advantageous to surveys to estimate absolute abundance, as well as for mitigation purposes (e.g. in the context of use of military sonar or seismic surveys), when it is vital to know when an animal is in the vicinity of potentially harmful human activities.

As has been shown in previous helicopter surveys (e.g., dolphins in the Eastern Tropical Pacific (Gerrodette and Forcada 2005)), one advantage of helicopters was the ability to halt the survey at any time and position the helicopter in a way in which detailed information on a sighting could be collected. This was especially true for the accurate determination of group size, where it was found that initial group size estimates of minke whales often increased during observation of the sighting in closing mode. The use of a digital camera from the helicopter served as an effective tool to identify whales on a species level. In the case of beaked whales, the use of digital photography in combination with the helicopter allowed the determination of species in which sightings are short and notoriously difficult to identify. This has allowed us to obtain records of poorly known species, such as Arnoux's beaked whale, the straptoothed whale and Gray's beaked whale.

Even though photo-identification during our helicopter survey was used as an opportunistic method, the data collected can provide valuable information. The matching of individual right whales between feeding and breeding grounds can offer insight into migration patterns and habitat use. Photo-identification catalogues of individual whales exist worldwide and are particularly important for those cetacean populations that occur in low numbers.

In summary, conducting helicopter surveys, even from platforms that cannot follow a systematic survey design, can be an efficient means to investigate cetacean distribution and abundance in the Southern Ocean. This is especially true for areas in which high ice coverage makes survey work with a non ice-breaking vessel impractical (e.g. the Weddell Sea). Nevertheless, it is difficult to conduct pre-designed surveys whilst working from a transiting research vessel. We see two options for overcoming this limitation. One is to be adaptive in survey design, including personnel with experience with survey design and data analysis, so that survey design algorithms can be used to lay out tracklines in more or less real time as satellite ice images become available. The second option is to come up with what is thought to represent a reasonable solution in the field, and accept that some principles of good survey design will be violated due to uncertainty in ice conditions. This latter approach leaves the problems of poor survey design to be addressed at the analysis stage. In our case, our future analyses are going to be complicated immensely by the unequal coverage probability that stemmed from our ad hoc survey design (Bravington and Hedley 2009). In other words, one can bring an analyst into the field, or be pre- pared to spend additional time and resources on analysis post-cruise. The geographic complexity and dynamic nature of sea ice will always be a challenge to the design and execution of rigorous systematic surveys for whales in these regions. However, the flexibility and manoeuvrability of helicopters make them a powerful scientific tool with which to approach that challenge.

Acknowledgments A large number of people have provided valuable advice prior to the field work. This includes Horst Bornemann, Peter Boveng, Mark Bravington, Michael Cameron, Greg Donovan, Christian Haas, Sharon Hedley, John Jansen, Jeff Laake, Russell Leaper and Tony Warby. We would like to thank Captain Pahl and Captain Schwarze and the crew of RV 'Polarstern' for their logistical support. A special "thanks" goes to the helicopter crew, Jürgen Büchner, Hans Heckmann, Uli Michalski, Jens Brauer, Markus Heckmann and Carsten Möllendorf for professional and safe flights. We would also like to thank the meteorological office onboard the 'Polarstern', Frank-Ulrich Dentler, Klaus Buldt, Christoph Joppich, Harald Rentsch, Edmund Knutz and Felicitas Hansen for their excellent weather forecasts. A personal thanks goes to the scientist-in-charge Julian Gutt for his continuous support of this project prior to and during the ANT XXIII/8 survey. We thank Stefan Bräger, Helena Herr, Kristina Lehnert and Hans Verdaat for their dedicated observer work during ANT XXV/2. Thanks to Gunnar Spreen and his colleagues for providing AMSR-E ice concentration data. The two projects presented here were financed by a number of different institutions: Alfred Wegener Institute for Polar and Marine Research (AWI), Institute for Marine Resources and Ecosystem Studies (Wageningen IMARES), Johann Heinrich von Thünen Institute (Federal Research Institute for Rural Areas, Forestry and Fisheries), Research and Technology Centre Westcoast (FTZ) of the University Kiel, the Netherlands Polar Programme (NPP) of the Netherlands Organisation for Scientific Research (NOW), Dutch Ministry of Agriculture, Nature and Food Quality (LNV), German Federal Ministry of Food, Agriculture and Consumer Protection (BMELV) and the German Federal Ministry for the Environment, Nature Conservation and Nuclear Safety (BMU). The responsibility of the content of this publication lies with the author. We thank Natalie Kelly, Colin Southwell, Paige Eveson and one anonymous reviewer for helpful feedback on a previous version of this manuscript.

Open Access This article is distributed under the terms of the Creative Commons Attribution Noncommercial License which permits any noncommercial use, distribution, and reproduction in any medium, provided the original author(s) and source are credited.

\section{References}

Ainley DG, Dugger KKM, Toniolo VV, Gaffney II (2007) Cetacean occurrence patterns in the Amundsen and southern Bellingshausen sea sector, Southern Ocean. Marine Mammal Sci 23:287-305

Branch TA, Butterworth DDS (2001) Southern Hemisphere minke whales: standardised abundance estimates from the 1978/79 to 1997/98 IDCR/SOWER surveys. J Cetacean Res Manag 3:143174

Bravington MV, Hedley SL (2009) Antarctic minke whale abundance estimates from the second and third circumpolar IDCR/SOWER surveys using the SPLINTR model. Paper SC/61/IA14 presented to the Scientific Committee of the International Whaling Commission, June 2009 (unpublished)

Breiman L, Friedman JH, Olshen R, Stone CJ (1984) Classification and regression trees. Wadsworth International Group, Belmont, CA 
Buckland SST, Anderson DR, Burnham KP, Laake JL, Borchers DDL, Thomas L (2001) Introduction to distance sampling. Oxford University Press, Oxford

Clapham PJ, Berggren P, Childerhouse S, Friday NA, Kasuya T, Kellam P, Kock KH, Manzanilla-Nam S, Notabartolo di Sciara G, Perrin WF, Read AJ, Reeves RR, Rogan E, Rojas-Bracho L, Smith TD, Stachowitsch M, Taylor BL, Thiele D, Wade PPR, Brownell RL (2003) Whaling as science. Bioscience 53:210-212

ESRI (2009) ArcGIS-A complete integrated system. Environmental Systems Research Institute, Inc, Redlands, California

Friedlaender AS, Halpin PN, Qian SS, Lawson GL, Wiebe PH, Thiele D, Read AJ (2006) Whale distribution in relation to prey abundance and oceanographic processes in shelf waters of the Western Antarctic Peninsula. Mar Ecol Prog Ser 317:297-310

Friedlaender AS, Lawson GL, Halpin PN (2009) Evidence of resource partitioning between humpback and minke whales around the western Antarctic Peninsula. Marine Mammal Sci 25(2):402415. doi:10.1111/j.1748-7692.2008.00263.x

Friedlaender AS, Johnston DW, Fraser WR, Burns J, Patrick NH, Costa DP (2010) Ecological niche modeling of sympatric krill predators around Marguerite Bay, Western Antarctic Peninsula. Deep Sea Res II: topical studies in oceanography. doi:10.1016/ j.dsr2.2010.11.018

Gerrodette T, Forcada J (2005) Non-recovery of two spotted and spinner dolphin populations in the eastern tropical Pacific Ocean. Mar Ecol Prog Ser 291:1-21

Guisan A, Zimmermann NE (2000) Predictive habitat distribution models in ecology. Ecol Model 135:147-186

Gutt J (2008) The expedition ANTARKTIS-XXIII/8 of the research vessel "Polarstern" in 2006/2007 : ANT-XXIII/8; 23 November 2006-30 January 2007 Cape Town-Punta Arenas. Rep Polar Res 569:1-153

Gutt J, Barratt I, Domack E, d'Udekem d'Acoz C, Dimmler W, Grémare A, Heilmayer O, Isla E, Janussen D, Jorgensen E, Kock K-H, Lehnert LS, López-Gonzáles P, Langner S, Linse K, Eugenia Manjón-Cabeza M, Meißner M, Montiel A, Raes M, Robert H, Rose A, Sañé Schepisi E, Saucède T, Scheidat M, Schenke H-W, Seiler J, Smith C (2011) Biodiversity change after climate-induced ice-shelf collapse in the Antarctic. Deep Sea Res II: Topical Stu Oceanogr 58:74-83

Hammond PS, Benke H, Berggren P, Borchers DDL, Buckland SST, Collet A, Heide Jorgensen MMP, Heimlich Boran S, Hiby AAR, Leopold MF, Oien N (1995) Distribution and abundance of harbour porpoises and other small cetaceans in the North Sea and adjacent waters. European community LIFE programme, life 92-2/IL/027
Hazen EL, Friedlaender AS, Thompson MA, Ware CR, Weinrich MT, Halpin PN, Wiley DN (2009) Fine-scale prey aggregations and foraging ecology of humpback whales Megaptera novaeangliae. Mar Ecol Prog Ser 395:75-89. doi:10.3354/meps08108

Hedley SL, Buckland SST, Borchers DL (1999) Spatial modelling from line transect data. J Cetacean Res Manag 1:255-264

Moore SE, Huntington HP (2008) Arctic marine mammals and climate change: impacts and resilience. Ecol Appl 18:157-165

Plötz J, Weidel H, Bersch M (1991) Winter aggregations of marine mammals and birds in the north-eastern Weddell Sea pack ice. Polar Biol 11:305-309

Redfern JV, Ferguson MC, Becker EA, Hyrenbach KD, Good C, Barlow J, Kaschner K, Baumgartner MF, Forney KA, Ballance LT, Fauchald P, Halpin P, Hamazaki T, Pershing AJ, Qian SS, Read A, Reilly SB, Torres L, Werner F (2006) Techniques for cetacean habitat modeling. Mar Ecol Prog Ser 310:271-295. doi:10.3354/ meps310271

Richardson J, Green C, Malme C, Thomson D (1995) Marine mammals and noise. Academic Press, 525 B Street, San Diego, California, USA. pp 92101-4495

Roberts JJ, Best BD, Dunn DC, Treml EA, Halpin PN (2010) Marine geospatial ecology tools: an integrated framework for ecological geoprocessing with ArcGIS, Python, R, MATLAB, and C++. Environ Modell Softw 25:1197-1207. doi:10.1016/j.envsoft. 2010.03.029

Southwell C (2005) Optimising the timing of visual surveys of crabeater seal abundance: haulout behaviour as a consideration. Wildlife Res 32:333-338

Spreen G, Kaleschke L, Heygster G (2008) Sea ice remote sensing using AMSR-E 89-GHz channels. J Geophys Res 113(C2):C02S03. doi: $10.1029 / 2005$ jc003384

Thiele D, Chester ET, Moore SE, Sirovic A, Hildebrand JA, Friedlaender AS (2004) Seasonal variability in whale encounters in the Western Antarctic Peninsula. Deep Sea Res II: Topical Stu Oceanogr 51:2311-2325. doi:10.1016/j.dsr2.2004.07.007

Thomas L, Williams R, Sandilands D (2007) Designing line transect surveys for complex survey regions. J Cetacean Res Manag 9:1-13

van Franeker JA, Bathmann UV, Mathot S (1997) Carbon fluxes to Antarctic top predators. Deep Sea Res II 44:435-455

Williams R, Hedley SL, Hammond PS (2006) Modeling distribution and abundance of Antarctic baleen whales using ships of opportunity. Ecol Soc 11:1 http://www.ecologyandsociety.org/vol11/ iss 1/art1. Accessed 20 March 2011 